\title{
AN ITERATIVE MODAL SHIFT MODEL OF LONG DISTANCE RAIL PASSENGERS TOWARDS AIR TRANSPORT IN INDIA
}

\author{
Thamizharasan Venkatachalam ${ }^{1}$, Karthik K. Srinivasan ${ }^{2}$, Nivetha Nithiyanandam ${ }^{3}$, \\ Sivaranjani Rajakamangalam Sivathanupillai ${ }^{4}$, Sivasankari Rajendran ${ }^{5}$, Sree Swathi \\ Jayasankar $^{6}$, Selvakumar Muthusamy ${ }^{7}$ \\ 1,2 Transportation Engineering Division, Department of Civil Engineering, Indian Institute of Technology \\ Madras (IITM), Chennai, India \\ $3,4,5,6,7$ Department of Civil Engineering, Sri Venkateswara College of Engineering (SVCE), \\ Sriperumbudur, India
}

Received 26 July 2020; accepted 2 September 2020

\begin{abstract}
In India, long distance (greater than 1,000 km trip length) travel is accomplished by air \& rail transport modes. After initiation of 'Open Sky Policy', private airlines were enrolled in air travel market under the name of Low Cost Airlines (LCA). Due to stiff competition among carriers, all the airlines are reducing fares to bolster their markets. The aim of such cuts is, partially, to attract other mode users. Such reduced fares may be tempting upper class rail travellers, particularly I AC (most gorgeous coach) and II AC (2-tier AC) passengers who can spare the air fare. In this background, a modal shift model was developed to understand the driving forces and key factors influencing the shift from upper class rail to air by conducting a Stated Preference (SP) survey among upper class rail passengers in the year 2007 (then the air fare was $50-60 \%$ higher than I AC rail fare). A similar study was conducted in the year 2019 (air fare was 10-20\% higher than I AC rail fare) and a model was developed with the same set of parameters that had been significant in 2007 by applying binary logit technique to understand the implications in the current economic outline. It was observed that the fare difference between rail \& air arouses significantly in inducing switch to air mode in both the cases. However, segments like 'high income passengers' and 'passengers had travel experience in air' had exhibited denial behaviour under the current situation.
\end{abstract}

Keywords: iterative model, rail, modal shift, India, air transport.

\section{Introduction}

Intercity mode choice analysis generally appears in transportation planning where one is concerned in the distribution of traffic within a given intercity corridors among available modes of transport. In short distance corridors, the choice is often between road and rail transportation, although in long distance (distance more than one thousand kilometers) corridors the choice is among air and rail.

\subsection{Inter-modal Competition in Indian Intercity Travel Market}

Before 1990, the rail and air modes were operated \& owned by the Government (monopoly market). In that period, the air fare was much above than the air conditioned

\footnotetext{
${ }^{7}$ Corresponding author: msk@svce.ac.in
} 
I Class (I AC) rail fare. Private airlines were not present in the long distance travel market. In between 1990 - 2000, private airlines were enrolled in the market and few of them have subsequently quieted their services.

Hence, there was not much competition (inter-modal) in both the phases. However, after 2000, once again the private operators entered the air travel business market, mainly, in the form of Low-Cost Airlines (LCA).

After 2004, as the number of private airlines expanded, tight competition (intra-modal) among carriers led to fare reduction and the consequent growth in long-haul intercity traffic created a new inter-modal competition between upper class rail and air transport.

In India, as explained above, due to tough competition among air operators, all airlines were decreasing fares to attract other mode users (rail). Such reduced fares may be appealing to upper class rail travellers, particularly I AC (most luxurious coach, refer Annexure I) and II AC (2-tier AC) passengers who can 'manage' the air fare.

Thus the air fare on an average, 50-60\% higher than the I AC rail fare in 2007, was 10-20\% higher in 2019 as shown in Table 1. Hence, the iterative study is still relevant in the year 2019 .

\section{Table 1}

Travel Cost (in Rs. (in $€$ )): Chennai - New Delhi

\begin{tabular}{|c|c|c|}
\hline Mode & $\mathbf{2 0 0 7}$ & $\mathbf{2 0 1 9}$ \\
\hline Air & $7,266^{*}(85.55)$ & $5,551^{*}(65.36)$ \\
\hline Rail (I AC) & $3,609(42.49)$ & $5,190(61.11)$ \\
\hline
\end{tabular}

Note: *Various depend on City-pair \& Time-of-Day

Source: (Indian Railways, 2019; Google Flights, 2019)

\section{Literature Review}

A few studies comparing models were done and widely spaced are discussed below.

A study was conducted to compare the application of two logit models for the analysis of qualitative marketing data (Flath et al., 1979). For this authors surveyed retail bank customers to characteristics thought related to probability of their having adopted a then introduced automatic teller service. A weighted least square (WLS) logit model was compared with a maximum likelihood logit model (MLM). The study concluded that logit model developed using MLM was efficient and economic.
A study was conducted to compare and evaluate the predictive ability of logit and probit models when applied in mode choice context (Ghareib, 1996). Two transit modes operating in different cities of the Saudi Kingdom were analyzed. From this study, it was suggested that not to calibrate the complicated models such as probit when analyzing the situation of a binary mode choice because logit models shows more accurate predictions.

A comprehensive research study was took place in Greece in order to investigate the process and the criteria for freight modal choice behavior (Moschovou et al., 2012). Two models were developed: (1) 
Conventional linear regression model and (2) Disaggregate logit model. The study concluded that the model developed using disaggregate data could be very useful in assessing policy measures.

To understand the mode choice behaviour in choosing bus (public transport) and private vehicles, a face-to-face interview survey was conducted among travellers in Baghdad (Iraq) (Hussain et al., 2017). Two models were developed using multinomial logistic regression and artificial neural networks methods. The results shown that artificial neural network was readily outperformed the multinomial logistic regression in predicting mode choice.

\section{Methodology}

Following methodology was adopted for comparing logit models of two different periods:

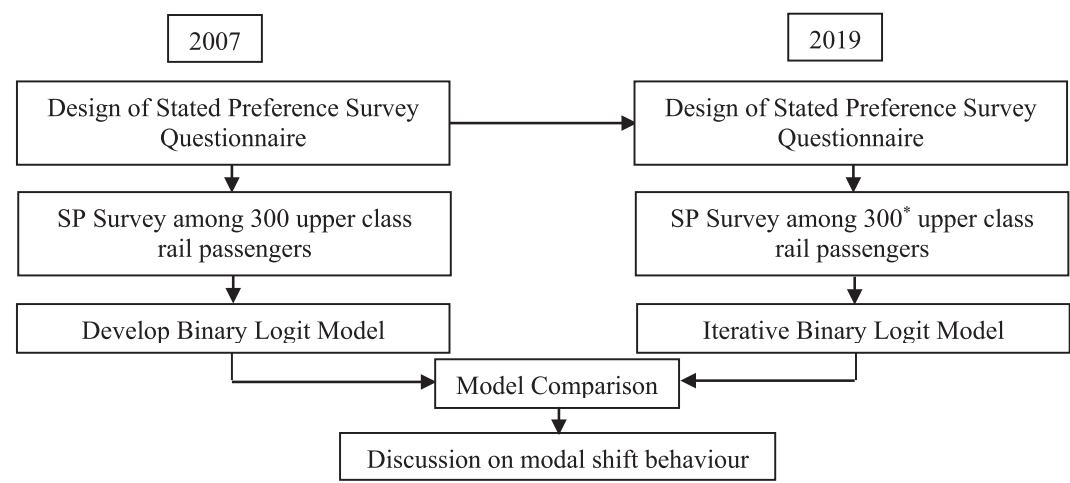

Fig. 1.

Study Approach

Note: *Assuming that 10 significant variables in the final model and each independent variable requires 30 data points for better correlation with dependent variable (Cohen, 1988)

A modal shift model was developed to recognize the driving forces inducing transfer of upper class rail travellers to air mode using Stated Preference (SP) survey among rail passengers in the year 2007. A similar study was conducted in 2019 and an iterative model was developed (same set of attributes) so as to evaluate the attitudinal changes towards air transport under the current economic outline. The SP survey proposed with four fare scenarios (Table 2). Still the air fare is higher than I AC rail fare, below scenarios were valid in 2019 also.

Table 2

SP Hypothetical Scenarios

\begin{tabular}{|c|c|c|}
\hline Scenario & Fare difference & Meaning \\
\hline I & $0 \%$ & Air fare is equal to I AC Rail fare \\
\hline II & $10 \%$ & Air fare is 10\% higher than I AC Rail fare \\
\hline III & $20 \%$ & Air fare is 20\% higher than I AC Rail fare \\
\hline IV & $30 \%$ & Air fare is 30\% higher than I AC Rail fare \\
\hline
\end{tabular}


The survey was carried out among I AC \& II AC rail passengers. The long distance trains originating from Chennai to other major metropolitan cities like New Delhi, Mumbai and Kolkata were chosen. A faceto-face interview survey was conducted with passengers. Since, it has the following advantages compared to other data collection methods. They are: (1) the survey takes less time. Since, there is no postal lags; (2) method gives higher reply rate due to personal interaction than mail back surveys and (3) it is possible for the surveyor to determine and resolve unfilled questions immediately.

\section{Model Details}

The model detail is important to know how model looks. The model specification of the 'modal shift model' is given in eq. 1 .
$\mathrm{P}_{\text {shift }}=\frac{e^{V}}{1+e^{V}}=\frac{e^{B_{0}+B_{1} X_{1}+B_{2} X_{2}+\ldots \ldots+B_{n} X_{n}+\varepsilon}}{1+e^{B_{0}+B_{1} X_{1}+B_{2} X_{2}+\ldots \ldots .+B_{n} X_{n}+\varepsilon}}$

Where, $\mathrm{P}_{\text {shift }}=$ Probability of shift from rail to air mode;

$V=$ Deterministic Utility function of the rail mode;

$B_{0}, B_{1}, B_{2} \ldots$ are the model coefficients to be calibrated (model calibration);

$X_{1}, X_{2} \ldots$ are variables which affecting probability of shift.

\section{Comparison of Socio-economic Profile of Upper Class Rail Passengers}

Figure 2 compares the socio-economic profile of upper class rail travellers for the years $2007 \& 2019$.
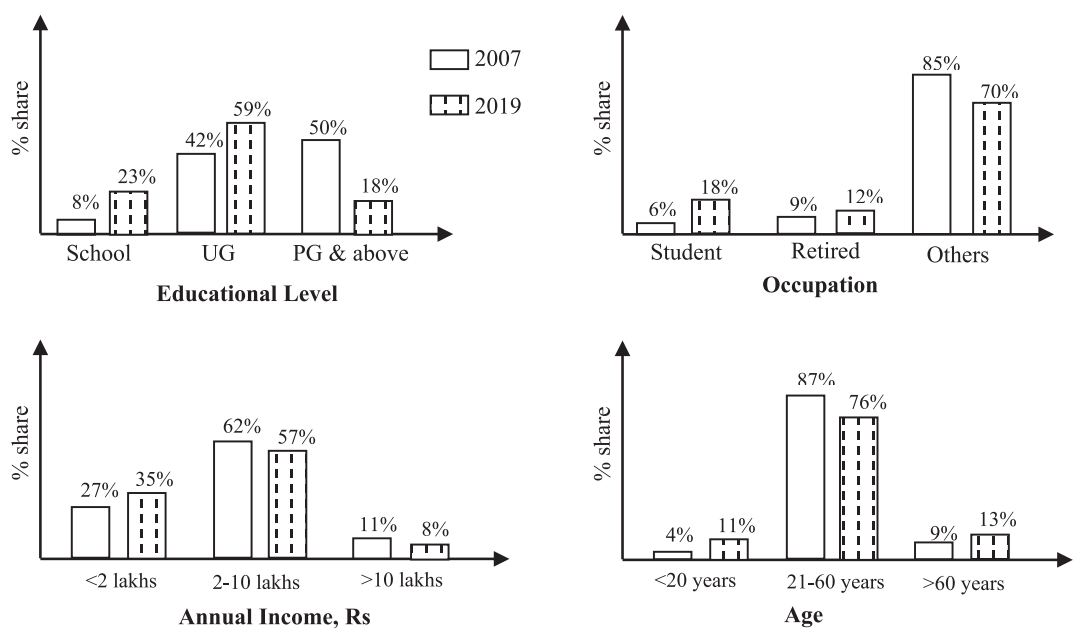

Fig. 2.

Comparison of Socio-economic Profile of Upper Class Rail Travellers 
Following inferences were arrived:

- $50 \%$ of travellers were having education level as Post-graduate or above in 2007, reduced to $18 \%$ in 2019 ;

- $18 \%$ are of the travellers were falls in students category in 2019 which was only $6 \%$ in 2007 ;

- There was little change in higher income (annual income $>10$ lakhs $\approx 11,774 €$ ) category of travellers;
- $11 \%$ of travellers (mostly students) fall in the age of 20 or below in 2019, whereas, it was $4 \%$ in 2007.

\section{Model Calibration}

The aim of this study is to iterate the model with same set of parameters which was developed in 2007 by using new SP data set collected in 2019. Collected data was coded and run using Statistical Software Tools (SST) software and were compared with 2007 model as given in Table 3 below:

Table 3

Model Comparison: 2007 vs. 2019

\begin{tabular}{|l|c|c|c|c|}
\hline \multirow{2}{*}{ Causal Factor } & \multicolumn{2}{c|}{2007 Model } & \multicolumn{2}{c|}{2019 Model } \\
\cline { 2 - 5 } & Coefficient & $t$ stat. & Coefficient & $t$ stat. \\
\hline Constant term & 1.846 & 6.26 & 2.503 & 8.47 \\
\hline Passenger with annual income > Rs.10 lakhs $(11,774 €)$ & 0.753 & 2.78 & -0.593 & -1.71 \\
\hline Self-employed passengers & -0.581 & -2.77 & 0.457 & 2.15 \\
\hline Passengers who perceive that air travel is 'not that costly' & 0.710 & 4.15 & 0.360 & 1.78 \\
\hline Advance trip planners & -0.334 & -1.30 & -0.325 & -1.48 \\
\hline Passengers travelled by air at least once & 0.579 & 3.06 & -0.315 & -1.49 \\
\hline Passengers who did not travel by air yet & -0.563 & -2.70 & 1.138 & 4.39 \\
\hline Personal trip makers & -0.429 & -2.74 & 0.561 & 2.61 \\
\hline Passengers travelling in II AC coach & -0.727 & -2.99 & 0.013 & 0.06 \\
\hline Fare difference & -14.233 & -16.56 & -22.680 & -18.53 \\
\hline Initial log-likelihood $\left(\mathrm{L}_{0}\right)$ & \multicolumn{2}{|c|}{-831.78} & \multicolumn{2}{|c|}{-831.78} \\
\hline Final log-likelihood $\left(\mathrm{L}_{\mathrm{F}}\right)$ & -535.73 & & -415.91 \\
\hline Goodness-of-fit $\left(\rho^{2}\right)$ & \multicolumn{2}{|c|}{0.36} & & 0.50 \\
\hline
\end{tabular}

\section{Discussion of Model Results}

By comparing the two models, following observations were arrived.

Following causal factor lost its statistical significance in inducing shift when compared to 2007 situation:

- Passengers travelling in second AC coaches $(t$ stat. $=+0.06)$.

Following segments of upper class rail travellers were changed their attitudes towards air transport:

- Self-employed passengers (disutility $\rightarrow$ utility);

- $\quad$ Passengers who did not travel by air yet (disutility $\rightarrow$ utility);

- Personal trip makers (disutility $\rightarrow$ utility);

- Passengers with annual income $>$ Rs.10 lakhs (utility $\rightarrow$ disutility);

- Passengers travelled by air at least once (utility $\rightarrow$ disutility). 
It can be concluded that self-employed travellers, passengers those who did not travel by air \& personal trip makers were more likely to use air transport under the current scenario. Whereas, higher income category travellers (> Rs.10 lakhs) and passengers who already made air travel were less likely to use air mode. This implies that the other income groups were likely to use air mode.

Following segments of upper class rail travellers were mirrored the same attitudes towards air transport:

- Passengers who perceive that air travel is 'not that costly' (utility);

- Advance trip planners (disutility).

Upper class travellers who perceive that air travel is not that costly were more likely to use air mode in both the periods. However, advance trip planners were not willing to use air transport.
In both the cases, fare difference was acting as a major driving force in deciding modal shift behaviour.

\section{Price Elasticity of Demand (PED)}

By comparing both the models, it was clear that 'fare difference' is a major driving force behind modal shift in both the time periods. However, fare change (price sensitivity) may not have same effect on all the segments of upper class rail travellers. Hence, it is of interest of study the effects of fare change on selected segments in modal shift behaviour were presented in Table 4. Here, the price elasticity of logit $(E)$ is estimated by (Ben-Akiva \& Lerman, 1985):

$E=\frac{\partial P / p}{\partial C / C}$

where, ${ }^{O P} / P$

$=$ Percentage change in probability of shift; $\partial C / C=$ Percentage change in the fare difference

\section{Table 4}

Price Elasticity of Demand for Selected Segments of Upper Class Rail Passengers

\begin{tabular}{|c|l|c|c|}
\hline \multirow{2}{*}{ S1. No. } & \multicolumn{1}{|c|}{ Type of Segment } & \multicolumn{2}{c|}{ PED } \\
\cline { 3 - 4 } & & 2007 & 2019 \\
\hline 1. & Personal trip makers who have not made air travel yet & 1.342 & 2.092 \\
\hline 2. & Personal trip makers & 1.455 & 1.968 \\
\hline 3. & Self-employed with > Rs. 10 lakhs who have travelled in air within six months & 1.719 & 1.689 \\
\hline 4. & II AC rail Passengers & 1.129 & 1.671 \\
\hline 5. & Annual Income>Rs. 10 lakhs who said air is not that costly & 1.840 & 1.706 \\
\hline
\end{tabular}

From above table, personal trip makers who have not made air travel yet are found to be more price sensitive when compared to other segments in the current situation. That is, if $1 \%$ change of air fare will induce $2.092 \%$ change in probability of shift in that segment.

\section{Conclusions}

The present study compares two modal shift models of different time periods (2007 \& 2019) to understand the attitudinal changes in shift behaviour of long distance upper 
class rail passengers towards air transport in India. From the study, following conclusions were arrived:

- Self-employed travellers, passengers those who did not travel by air, personal trip makers with annual income less than Rs. 10 lakhs $(11,774 €)$ were more likely to use air mode under the current scenario. However, Personal trip makers who have not made air travel yet were found to be price sensitive than other segments of travellers;

- Upper class travellers who perceive that 'air travel is not that costly' were more likely to use air mode in both the periods;

- Fare difference was found to be a major driving force in deciding modal shift irrespective of time.

\section{Annexure I}

The First Class AC (I AC): This is the most expensive class, with fares which can on par with airlines. This air conditioned coaches is present only on popular routes between metropolitan cities and can carry 18 passengers. The coaches are carpeted, having sleeping accommodation with privacy features like personal coupes.

AC-Two Tier: Air conditioned coaches with sleeping berths, ample leg room, curtains and individual reading lamps. Bedding and food is included with the fare. Broad gauge coach can carry 48 passengers.

\section{Acknowledgement}

Author expresses his profound gratitude to his research guides Prof. Thamizharasan Venkatachalam and Prof. Karthik K.Srinivasan, Transportation Engineering Division, Department of Civil Engineering, IIT Madras for their guidance and invaluable suggestions during the course of his research work (2002-2007). Also, he is indebted to Sri Venkateswara College of Engineering (SVCE), Sriperumbudur (India) for supporting his project work and providing all the necessary facilities.

\section{References}

Ben-Akiva, M.E.; Lerman, S.R. 1985. Discrete Choice Analysis: Theory and Application to Travel Demand. MIT Press, $390 \mathrm{p}$.

Cohen, J. 1988. Statistical Power Analysis for the Behavioural Sciences. $2^{\text {nd }}$ edition, Lawrence Erlbaum Associates, New York. 579 p.

Flath, D.; Leonard, E.W. 1979. A comparison of two logit models in the analysis of qualitative marketing data, Journal of Marketing Research 16(4): 533-538.

Ghareib, A.H. 1996. Evaluation of logit and probit models in mode-choice situation, Journal of Transportation Engineering 122 (4): 282-290.

Google Flights. 2019. Flights. Available from Internet: <https://www.google.com/flights?>. [Accessed on 09 Feb 2019].

Hussain, H.D.; Mohammed, A.M; Salman, A.D.; Rahmat, R.A.B.O.K.; Borhan, M.N. 2017. Analysis of transportation mode choice using a comparison of artificial neural network and multinomial logit model, ARPN Journal of Engineering and Applied Science 12(5): 1483-1493.

Indian Railways. 2019. Indian Railways Passenger Reservation Enquiry. Available from Internet: <http:// www.indianrail.gov.in/enquiry/FARE/FareEnquiry. html?locale $=\mathrm{en}>$. [Accessed on $09 \mathrm{Feb} 2019]$.

Moschovou, T.P.; Giannopoulos, G.A. 2012. Modeling freight mode choice in Greece, Procedia - Social and Behavioral Sciences 48: 597-611. 